\title{
Les éclats du rire. La culture des rieurs au XVIII siècle.
}

\section{Annie Duprat}

\section{OpenEdition \\ Journals}

Édition électronique

URL : https://journals.openedition.org/ahrf/1156

DOI : 10.4000/ahrf.1156

ISSN : $1952-403 X$

Éditeur :

Armand Colin, Société des études robespierristes

Édition imprimée

Date de publication : 1 septembre 2001

Pagination : 145-147

ISSN : 0003-4436

Référence électronique

Annie Duprat, "Les éclats du rire. La culture des rieurs au xvIII siècle. », Annales historiques de la

Révolution française [En ligne], 325 | juillet-septembre 2001, mis en ligne le 22 avril 2004, consulté le 23 avril 2022. URL : http://journals.openedition.org/ahrf/1156 ; DOI : https://doi.org/10.4000/ahrf.1156

Ce document a été généré automatiquement le 23 avril 2022.

Tous droits réservés 


\title{
Les éclats du rire. La culture des rieurs au XVIII ${ }^{\mathrm{e}}$ siècle.
}

\author{
Annie Duprat
}

\section{RÉFÉRENCE}

Antoine De Baecque, Les éclats du rire. La culture des rieurs au xviiie siècle, Paris,

Calmann-Lévy, 2000, 341 p.

1 Les recherches d'Antoine De Baecque s'inscrivent dans une perspective renouvelée de l'histoire de la Révolution française, celle qu'il est convenu à présent de nommer , histoire des idées et de représentations, figurées ou mentales. À la suite de travaux dont le nombre est impressionnant, il nous livre ce volume, recueil de six articles, dont quatre ont déjà été publiés, avec une introduction et une conclusion programmatiques qui appellent beaucoup de commentaires parce qu'elles ouvrent un débat de fond sur la question que l'on pourra schématiquement énoncer en ces termes: l'histoire dite culturelle peut-elle délibérément s'inscrire hors de toutes les règles de la méthode des historiens?

2 La perspective générale de l'auteur est celle d'une histoire de «la culture des rieurs au XVIII ${ }^{\mathrm{e}}$ siècle». Sa démarche a déjà été illustrée par un gros volume publié en 1988, La caricature révolutionnaire (CNRS Éditions), qui devait beaucoup à la qualité de l'abondante iconographie ainsi qu'aux travaux de Champfleury et de Bruel (le rédacteur du catalogue de la collection De Vinck du département des estampes de la B.N.F.) puis par le dossier thématique sur le rire, qu'il avait personnellement dirigé pour la revue des Annales Histoire Sciences sociales (mai-juin 1997). Préparant une thèse de doctorat en histoire moderne sous la direction de Michel Vovelle, Antoine De Baecque avait dépouillé, et partiellement étudié près de 6000 pamphlets et petites brochures parus avant et pendant la Révolution (le terminus a quo se situant autour de 1750) dans une quête du «corps de la Révolution». En rédigeant son premier grand livre, Le corps de l'histoire. Métaphore et politique, 1770-1800 (Calmann-Lévy, 1993) il nous apportait une 
pensée originale et parfois téméraire eu égard aux conditions de la recherche en histoire de la Révolution. Le fil conducteur de son enquête se situait alors dans une dialectique entre les écrits de Louis-Sébastien Mercier lorsqu'il décrit les corps souffrants mutilés des héros de la Révolution (qu'il s'agisse de Le Peletier de SaintFargeau ou des victimes de la Terreur) pour mieux la dénoncer, et ceux de Joseph-Antoine Cerrutti pour qui les formes corporelles expriment (et révèlent) une pensée et une tradition culturelle ancienne. Analysant la métaphore du corps, il saisit le passage des corps monstrueux, corps aristocratiques relevant d'une culture moribonde aux corps transformés par le projet de régénération des mœurs, des pensées et des référents politiques et culturels de la Révolution. La «défaite du corps du roi» et l'émergence du grand corps des citoyens grâce à «Sieyès docteur du corps politique», passe par l'action de mais aussi par les écrits, dans la presse en particulier, qui conduisent à un "grand spectacle de la transparence», par les fêtes des «corps du carnaval politique» ${ }^{1}$ et aussi, in fine, par (1). Suivant patiemment son fil d'Ariane, Antoine De Baecque est logiquement revenu sur la question de la mise en scène, à défaut de mise en image, de la mort sous la Terreur dans La gloire et l'effroi. Sept morts sous la Terreur (Grasset, 1997).

3 Ces deux livres ont été l'objet d'appréciations contrastées. On pouvait en effet ne pas accepter sans discussion la de l'auteur qui prône une approche en faisant l'éloge de la "source_touffue», qui se résume trop souvent en une juxtaposition sans lien de corrélation de sources de nature hétérogène; en multipliant les citations, souvent données comme argument définitif à la démonstration sans examen préalable approfondi, et en privilégiant les références à une historiographie américaine (la new cultural history) contestable à bien des égards, Antoine De Baecque ne craint pas les critiques. Bien au contraire, en analysant lucidement dans la revue Le débat (mars-avril 1999) l'échec du «tournant critique» lancé dixans auparavant par les Annales ESC, s'il avait repéré quelques faiblesses (de l'historiographie anglo-saxonne en particulier), il avait fait porter la responsabilité de l'échec constaté sur les historiens universitaires français, coincés dans un académisme suranné, obsédés par la préparation des concours de recrutement et par des rivalités de pouvoirs. Dans l'introduction de ces Éclats du rire, il reprend son plaidoyer pro domo en faveur d'une histoire culturelle qui serait la matrice de l'innovation parce qu'elle est mobile, curieuse, paradoxale et doit "résister par nature, à l'académisation de la discipline. Ces prises de position intransigeantes, voire désobligeantes à l'égard de ceux qui ne partageraient pas tous ses partis pris méthodologiques (ou a-méthodologiques?) si elles ont la vertu de la constance et de la détermination, présentent, par leur caractère tranché et radical, le grave défaut de fermer toute discussion.

4 Malgré ces réserves, Les Éclats du rire, le dernier ouvrage d'Antoine De Baecque, est une contribution importante et originale à l'histoire anthropologique de la culture politique du XVIII siècle à partir de la question du rire, de ses origines, de ses manifestations et de ses pratiques. Dans cette «politique des émotions», l'auteur repère trois sortes de rires: le rire aristocratique de la faction satyrique (illustré par les articles , précédemment publié dans les Annales HSS, mai-juin 1997, et «la Faction satyrique», publié dans Mots, septembre 1996; la gaieté, rire joyeux dans la tradition rabelaisienne (article , publié dans History of European Ideas, 1993); la farce, le rire vulgaire de la rue, des théatres populaires et surtout du cabaret de Ramponneau (article original ). Ce schéma est nuancé par la mise en évidence de passerelles; d'une part, Cerutti, jésuite défroqué, développe un véritable projet didactique et révolutionnaire fondé sur le rire 
dans La feuille villageoise; d'autre part, le journaliste patriote Gorsas crée une culture politique révolutionnaire par le rire dans Le courrier de Gorsas (article original, ). Enfin, dans un chapitre, , publié dans A cultural history of humour, ss dir. J. Bremmer et $\mathrm{H}$. Roodenburg, Londres, 1997, il reprend en croisant les débats d'assemblée et la lecture de journaux qu'il qualifie des les occasions de rire au cours des deux premières années de débats de l'Assemblée. Dans cette étude l'auteur, qui tente un comptage (retour ponctuel à une vieille histoire quantitative?) relève 400 éclats de rire en 28 mois: on se permettra de penser qu'en l'occurrence l'hétérogénéité du corpus risque d'invalider pareils résultats.

5 La conclusion de ce livre, en un bref chapitre intitulé nous entraîne, en une multitude de parcours tellement diversifiés que l'on s'y perd quelque peu; successivement, du début du xixesiècle lorsque Stendhal affirme que la suppression des privilèges a mis fin au principe de la comédie en France, à l'époque de Baudelaire, fasciné par l'ambiguïté du pouvoir de la caricature, les avis évoluent; le xxesiècle quant à lui aurait inventé un nouvel âge démocratique du rire, le rire parodique et de dérision (référence aux comme un passage obligé, très mode). À la lecture de cette conclusion le projet scientifique du livre apparaît cohérent. Cependant, qu'il me soit permis, mais je suis sans doute aveuglée par (3), d'énoncer quelques réserves et de suggérer quelques compléments à l'étude d'Antoine De Baecque. Le premier point porte sur la perspective chronologique qui couvre l'ensemble du xxesiècle mais ne cesse de présenter la Révolution en toile de fond. Étudier les écrits et les réseaux relationnels de Gorsas, Cerutti, Ginguené, d'une part, Champcenetz, Palissot, Rivarol et les autres membres de «la_faction_satyrique» au cours des années 1770-1780 en les croisant avec leurs prises de position et leurs actions pendant la période révolutionnaire biaise la source et transforme les conclusions. Les rédacteurs des Actes des Apôtres mènent un combat politique et militant sur le mode d'un rire qui emprunte ses références au rire de foire et de cabaret (donc le cirque de Nicolet, mais aussi la taverne de Ramponneau) pour mieux stigmatiser les assemblées parlementaires, les sociétés populaires et autres clubs révolutionnaires. Le perpétuel va-et-vient de mots et de figures (graphiques et mentales) entre patriotes et royalistes est trop négligé dans ce livre, bien qu'il ait déjà fait l'objet de travaux en France. Les articles consacrés au rire aristocratique («le Régiment de la calotte» et la «Faction satyrique») font progresser le dossier de la culture de ceux qui deviendront d'ardents royalistes pendant la Révolution (même si le premier a soulevé des critiques de la part d'Henri Duranton qui annonce un nouvel article dans la revue Dix-Huitième siècle, $\mathrm{n}^{\circ} 33 / 2001$ ). Le dossier Ramponneau s'avère encore beaucoup plus important, et plus problématique encore que ne l'annonce l'auteur, qui a fondé son étude essentiellement sur des sources de seconde main et une historiographie du XIX siècle (Brazier, Rannié, Dulaure etc.); dans une des récentes livraisons de la Revue d'Histoire moderne et contemporaine on peut lire que, dès 1761,l'expression «messe à la Ramponneau» était familièrement employée à Laval(4): cette observation n'est pas anecdotique puisqu'elle montre que Ramponneau était déjà fameux avant la signature d'un contrat pour des parades de rue avec Gaudon en avril $1761 . .$. Enfin, on aurait aimé lire quelques développements sur les rapports entre les lieux de la culture bachique, de la culture de la farce, des carnavals et des charivaris qui paraissent si présents au xviriesiècle dans le livre d'Antoine De Baecque et les autres lieux de sociabilités du siècle des Lumières, les salons, les cafés, les académies, les 
sociétés savantes et les loges maçonniques qui sont au cœur des préoccupations de l'historiographie française de ces trente dernières années.

6 En conclusion, si cet ouvrage peut susciter des critiques qui sont autant d'hommages à sa nouveauté, elles ne se situent pas là où l'annonçait l'auteur. En effet, le problème ne réside pas dans une histoire culturelle (ou, mieux, une «new cultural history») qui serait rejetée par les historiens «académiques», mais dans le recours trop abondant à des sources anciennes ou de seconde main: si l'historien doit se nourrir des écrits antérieurs, il doit enrichir sa réflexion de connaissances renouvelées grâce au contact avec les documents-source de première main. Néanmoins, on retirera de ce livre très riche des idées neuves, originales et très stimulantes qui devraient élargir la voie à de nouveaux horizons de recherche.

\section{NOTES}

1.Les formules placées entre guillemets sont quelques-uns des titres de chapitres du Corps de l'histoire.

1.Les éclats du rire, p. 21

INDEX

Mots-clés : imagerie populaire 